\title{
Fund-Raising Management of Chinese University Foundations from the Perspective of Alumni Donation Willingness: A Case of Universities in Hennan Provice
}

\author{
Qiuyang Bai ${ }^{1}$, \& Manoch Prompanyo ${ }^{1}$ \\ ${ }^{1}$ PhD Candidate, School of Management, Shinawatra University, Thailand \\ Correspondence: Qiuyang Bai, 99 Moo 10 Bang Toey, Sam Khok District, Pathum Thani 12160, Thailand.
}

Received: March 16, 2020

Accepted: June 8, 2020

Online Published: June 23, 2020

doi:10.5539/ibr.v13n7p108

URL: https://doi.org/10.5539/ibr.v13n7p108

\begin{abstract}
This article reviews the research results of a large number of Chinese and foreign scholars, and combines social identification theory, social exchange theory, social capital theory, stakeholder theory, and principal-agent theory to build a model of individual donation willingness in Chinese universities. The questionnaire was designed, and after collecting and analyzing the data, the hypothesis was verified, and the regression relationship between willingness to donate and different motivations was obtained through response analysis. In addition, this article takes alumni identity as an intermediary variable, and studies the interaction between donation motivation, alumni identity, and willingness to donate.

Based on the above research, this article concludes that there is a strong correlation between the motivation and willingness of individuals to donate to universities. Among them, reputation motivation, social responsibility realization, consolidate the relationship, tax incentives, and warm motivation have a significant effect on the willingness to donate. In addition, there is a strong correlation between alumni identity and willingness to donate. It is believed that these research conclusions can enable universities to recognize the purpose of individual donations, and to raise funds more effectively and reasonably for these motivations, thereby expanding the source of school funding and achieving sustainable development of the school.
\end{abstract}

Keywords: fund-raising management, Alumni donations, Alumni donation willingness, donation motivation

\section{Introduction}

Alumni donation is a core indicator for evaluating world-class universities. It is the normal state of world-class universities in Europe and the United States. It is a world-class university such as Harvard University and Yale University. It demonstrates its comprehensive strength, school level, quality of education and teaching, campus culture, social impact, and international influence. It has become a major indicator of the quality of world-class universities' education and teaching, social influence, alumni business achievements, alumni work effectiveness, and school governance capabilities. In recent years, the highest records of total alumni donations, individual donations, single donations, and alumni donation rates have been continuously refreshed. China University Evaluation Consultant Expert, Reporting Leader and Dean of Ericsson Institute Zhao Dezhou pointed out that in order to promote the alumni donation culture of China University, encourage alumni to give back to their alma mater, encourage Chinese universities to continuously improve the quality of education and teaching, and promote the continuous improvement of alumni work, promote the development of China's higher education. Since 2010, China Alumni Association has released an exclusive list of Chinese university alumni donations for 9 consecutive years.

\section{Relevant Research in China and Abroad}

Through the research of representative literature on influencing factors of donation behavior in recent years, scholars mostly base their research on influencing factors of donation behavior from the perspectives of university characteristics, alumni's identity with their alma mater, and alumni's individual characteristics.

From the selection of research samples, most of them are based on well-known Chinese University alumni, such as Peking University, Tsinghua University and so on. Almost all the studies are focused on qualitative research, and most of them are interpreted from the perspective of economics, sociology or psychology, staying at the 
level of review, and seldom have a deeper discussion.

From the point of view of research methods, most domestic and foreign scholars use regression analysis and structural equation model.

From the results of the study, different scholars have come to the opposite conclusion because of the differences in research samples and methods, such as gender factors and the influence of school prestige on donation behavior. Okunade (1994) believes that age is positively correlated with donation behavior, while Lewei (2009) concludes that age is negatively correlated with donation behavior.

Through the research of the existing literature, it is found that the characteristics of universities, alumni's identity with their alma mater and alumni's characteristics are the basis for dividing the research on the influence of alumni's donation behavior. The social identity theory proposed by Tajfel (1986), the theoretical model of alumni's organizational identity proposed by Mael ; Ashforth (1992) and the social exchange theory proposed by Homans (1985) are the theoretical basis of this paper.

In terms of research direction, domestic scholars mostly analyze alumni donation behavior from the aspects of cultivation of donation culture, factors affecting donation, and Strategies of collecting donations, while few studies start from the perspective of university's own characteristics; from the perspective of research methods, domestic scholars mostly discuss university's social donation behavior from the perspective of qualitative analysis, such as literature research, and lack of empirical model of quantitative analysis.

According to above analysis it can be seen that although the school funds nervous, given China's university is the study of this article also has some, but most is limited to the introduction to foreign experience, even put forward some constructive Suggestions, but there is no foothold in China's current social background or from the perspective of deep social background and various substantive Suggestions, cause the low level of the research content and repeat more. In addition, the above analysis also shows that at present, most of the relevant academic fields in China only elaborate in theory, without specific analysis from the operational level, which, to a large extent, makes the research results unable to be applied in practice.

\section{Research Models and Hypothesis}

\subsection{Research Model Design}

This study combines the actual characteristics of higher education in China to build a research model to study the motivational objects that influence the personal donations of college alumni. This paper argues that there are five basic motivations for college alumni to donate to universities: reputation motivation, realize social responsibility, consolidation of school leadership, tax incentives, and warm motivation. Then design a corresponding questionnaire scale for each variable, and use two different analysis methods, reliability analysis and validity analysis, to test the scale part of the questionnaire to confirm that the questionnaire design is reasonable and credible; Based on the premise, then, descriptive statistics, t-test inference statistics, F-value analysis of variance, correlation analysis, and multiple regression of sample data are used to verify whether the hypothetical relationship between the conceptual models holds.

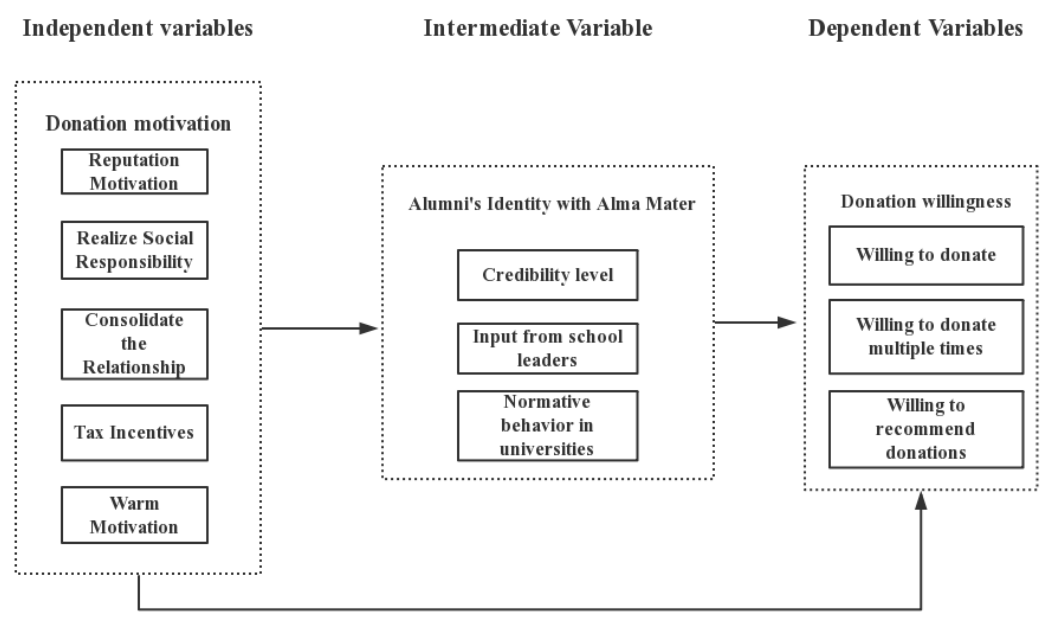

Figure 1. Model of Influencing Factors of Alumni Donation Willingness 


\subsection{Research Hypothesis}

H1: There is a positive correlation between alumna's identification with their Alma mater and willingness to donate.

$\mathrm{H} 2$ : There is a positive correlation between personal donation motivation and willingness to donate.

H3: There is a positive correlation between personal donation motivation and alumna's identification with their Alma mater.

\subsection{Data Collection Method}

This study is a quantitative study, using questionnaires to investigate the donation motivation of college students in Nanyang, Henan Province, China, and then using SPSS analysis to verify and analyze the collected data to draw relevant conclusions.

\subsection{Data Collection}

The author distributed the online questionnaire to the students of Nanyang Institute of Technology and used the questionnaire to sort out the questionnaire. A total of 423 questionnaires were distributed, 423 were actually recovered and 400valid questionnaires.

\subsection{Data Analysis}

This study is a quantitative study, so descriptive statistics(frequency, percentage, mean, standard deviation) are used to analyze and interpret the personal data of the interviewees. In addition, inferential statistics including ANOVA and multivariate regression were used to test variables and hypotheses at the level of significance.

Table 4.1. Results of Correlation Analysis between Variables

\begin{tabular}{|c|c|c|c|c|c|c|c|c|}
\hline & & $\mathrm{RM}$ & RSR & $\mathrm{CR}$ & TI & WM & AI & DW \\
\hline \multirow[t]{3}{*}{ RM } & Pearson Correlation & 1 & & & & & & \\
\hline & Sig. (2-tailed) & & & & & & & \\
\hline & $\mathrm{N}$ & 400 & & & & & & \\
\hline \multirow[t]{3}{*}{ RSR } & Pearson Correlation & $.367^{* *}$ & 1 & & & & & \\
\hline & Sig. (2-tailed) & 0 & & & & & & \\
\hline & $\mathrm{N}$ & 400 & 400 & & & & & \\
\hline \multirow[t]{3}{*}{$\mathrm{CR}$} & Pearson Correlation & $.285^{* *}$ & $.318^{* *}$ & 1 & & & & \\
\hline & Sig. (2-tailed) & 0 & 0 & & & & & \\
\hline & $\mathrm{N}$ & 400 & 400 & 400 & & & & \\
\hline \multirow[t]{3}{*}{ TI } & Pearson Correlation & 0.042 & $.168^{* *}$ & $.191^{* *}$ & 1 & & & \\
\hline & Sig. (2-tailed) & 0.399 & 0.001 & 0 & & & & \\
\hline & $\mathrm{N}$ & 400 & 400 & 400 & 400 & & & \\
\hline \multirow[t]{3}{*}{ WM } & Pearson Correlation & $.389^{* *}$ & $.370^{* *}$ & $.311^{* *}$ & $.175^{* *}$ & 1 & & \\
\hline & Sig. (2-tailed) & 0 & 0 & 0 & 0 & & & \\
\hline & $\mathrm{N}$ & 400 & 400 & 400 & 400 & 400 & & \\
\hline \multirow[t]{3}{*}{ AI } & Pearson Correlation & $.247^{* *}$ & $.342^{* *}$ & $.214^{* *}$ & 0.039 & $.199^{* *}$ & 1 & \\
\hline & Sig. (2-tailed) & 0 & 0 & 0 & 0.442 & 0 & & \\
\hline & $\mathrm{N}$ & 400 & 400 & 400 & 400 & 400 & 400 & \\
\hline \multirow[t]{3}{*}{ DW } & Pearson Correlation & $.449^{* *}$ & $.429^{* *}$ & $.319^{* *}$ & $.188^{* *}$ & $.464^{* *}$ & $.308^{* *}$ & 1 \\
\hline & Sig. (2-tailed) & 0 & 0 & 0 & 0 & 0 & 0 & \\
\hline & $\mathrm{N}$ & 400 & 400 & 400 & 400 & 400 & 400 & 400 \\
\hline
\end{tabular}

**. Correlation is significant at the 0.01 level (2-tailed).

\section{Correlation Analysis}

Correlation analysis is a quantitative analysis method to analyze the relationship between objective things. Graphical and numerical methods can be used to effectively reveal the strength of statistical relationships between things. If the data collected in this study are fixed distance data, the strength of the linear correlation between variables can be analyzed by calculating the Pearson simple correlation coefficient.

The correlation coefficient is a statistic describing the degree and direction of this linear relationship. Generally, 
the system default Pearson coefficient $r$ is used. When describing the degree of relationship, it is assumed that $r$ $<0.2$ is irrelevant, and when $0.2<\mathrm{r}=0.4$ Very weak correlation, weak correlation when $0.4<\mathrm{r}=0.6$, moderate correlation when $0.6<\mathrm{r}=0.8$, strong correlation when $0.8<\mathrm{r}=1$. In describing the direction, when $\mathrm{r}$ is a positive value, it is a positive correlation, and when $r$ is a negative value, it is a negative correlation, and its correlation degree corresponds to a positive value. The obtained correlation coefficient matrix is shown in Table 4.1:

(1) Correlation analysis between donation motivation and willingness to donate

From the above table analysis, it can be seen that the correlation coefficient between reputation motivation and donation willingness is 0.449 , which is significantly correlated at a significance level of 0.01 , indicating that there is a strong correlation between the two. The correlation coefficient between the achievement of social responsibility motivation and willingness to donate is 0.429 , which is significantly correlated at a significance level of $0.0,1$, indicating that there is a strong correlation between the two. The correlation coefficient between personal consolidation motivation and donation willingness is 0.319 , which is significantly correlated at a significant level of 0.01 , indicating that the two have a strong correlation. The correlation coefficient between tax incentives and donation willingness is 0.188 , which is significantly correlated at a significant level of 0.01 , and the correlation coefficient between warm motivation and donation willingness is 0.464 , which is significantly correlated at a significant level of 0.01 , indicating that the two have a strong correlation.

\section{(2) Correlation analysis between donation motivation and alumni identity}

Through the analysis of the results in Table 4.18, we can see that the Pearson correlation coefficients between reputation motivation, motivation to achieve social responsibility, motivation to strengthen relationships, warmth motivation, and alumni identity are $0.247^{* *}, 0.342 * *, 0.214 * *$, and 0.199 . **. Therefore, there is a correlation between reputation motivation, motivation to achieve social responsibility, motivation to strengthen relationships, warming motivation and sense of identity, while the Pearson correlation coefficient between tax incentives and sense of identity is 0.039 , and the p-value is $0.442>0.05$ There was no significant correlation at a significant level of 0.01 .

\section{(3) Correlation between alumni identity and willingness to donate}

Through the analysis of the results in Table 4.18, we can see that the Pearson

correlation coefficient between alumni identity and donation willingness is $0.308 * *$, which is significantly correlated at a significant level of 0.01 , indicating that the two have a strong correlation.

\section{Conclusion}

In the relevant analysis of alumni identity and donation motivation, reputation motivation and alumni identity are significantly positively correlated, indicating that donating to colleges with good quality, high visibility, and no violations of laws and disciplines will increase donors' reputation motivation. The achievement of social responsibility is significantly positively related to the credibility of universities and the standardization of school running behavior, which indicates that donations to universities with strong teachers, good student quality, high internal management level, and no bad school running behavior can make donors better. Help others and realize their altruistic intent to serve the community. There is no significant positive relationship between motivation for consolidation, tax incentives, warmth, and alumna's identity, indicating that alumni believe that there is no intermediary role in the impact of consolidation, tax incentives, and warmth on donation willingness. Do not consider the impact of these factors.

If an individual thinks that donating to a university can increase its own "recognition" and improve its social status, then the possibility of an individual donating to a university will be relatively large. In particular, the accuracy of the role of reputation benefits is more shown when the donation is public or the donation is obvious. If the behavior of donating colleges and universities can establish a relationship with school leaders, or can consolidate the existing interpersonal relationship through this kind of donation, the possibility of this kind of donation will also increase, and the warm motivation is also called by some scholars as a good idea. It is the foundation of many moral feelings, and it is the mutual help behavior of "building goodness and virtue". When some individuals feel that the quality of teaching in universities has fallen due to insufficient funds, which affects the growth of young people and feels intolerable, it also induces their behavior to donate to universities. Motivation of preferential taxation is a key factor affecting individual donation colleges and universities, and the taxation policy of charitable donations has a good incentive effect on taxpayers' charity. 


\section{References}

David, A. W., \& Paul, C. G. (1998). identity in organizations-Building theory through conversations. California: SAGE Publications, 08, 203-207

Le, W. (2009). Study on Psychological Characteristics and Influencing Factors of High Nucleus Friends Gift. Journal of Technical Supervision Education, 1, 59-64.

Lu, G. S. (2006). Analysis of Alumni Donation in Colleges and Universities and Its Influencing Factors. Journal of Shanxi Normal University, 35, 55-58.

Qiu, H. B. (2013). On Value Identity in the Construction of Donation Culture in Colleges and Universities. Academic exchange, 11, 196-199.

Qu, H. (2010). Research on the Influencing Factors of Alumni Donation Behavior in Public Universities. Huazhong University of Science and Technology.

Sung, M., \& Yang, S. (2009). Student-university relationships and reputation: a study of the links between key factors fostering students' supportive behavioral intentions towards their university. Higher Education, 57(6). https://doi.org/10.1007/s10734-008-9176-7

Wang, K. (2014). Private Foundations Donor-Wishes Risk Oriented Audit Model Studies. Nanjing University of Science and Technology, Nanjing.

Wang, Z. X. (2004). The Development and Innovation of Risk-Oriented Audit-Management Fraud-Oriented Audit. Accounting Research, 12, 49-54.

Zhang, J. H. (2012). An Investigation on the Organizational Elements of the Prosperity of Alumni Donations in American Universities. Comparative Education Research, 264, 82-86.

Zhou, H. L. (2016). Empirical Analysis on the Influencing Factors of Alumni Donation in Colleges and Universities. Higher education exploration, 7, 47-52.

\section{Copyrights}

Copyright for this article is retained by the author(s), with first publication rights granted to the journal.

This is an open-access article distributed under the terms and conditions of the Creative Commons Attribution license (http://creativecommons.org/licenses/by/4.0/). 